\section{Saúde pública e ética na era da medicina genômica: rastreamentos genéticos}

\section{Public health and ethics in the age of genomic medicine: genetic screening}

Flavia Miranda Gomes de Constantino Bandeira 1 Yara de Miranda Gomes 2 Frederico Guilherme Coutinho Abath 3

1,2 Departamento de Imunologia. Centro de Pesquisas Aggeu Magalhães. Fundação Oswaldo Cruz. Recife, PE, Brasil. CEP: 50.570-420, Rua Prof. Moraes Rego, s. n. Cidade Universitária. Recife, PE, Brasil. E-mail: flavia_band@hotmail.com 2 Hospital Fundação de Hematologia e Hemoterapia de Pernambuco. Recife, PE, Brasil.

\begin{abstract}
This article has the objective to bring the field of public health into context in the face of the great advances of biotechnology and applied genetics, focusing on issues related to the theme such as benefits and ethics concerning genetic screening. The Human Genome Project has generated many expectations among which the possibility of screening genes associated to diseases and behaviors, moreover, the possibility of genetic interventions on humans, creating concerns related to the resurgence of Eugenia, of genetic counseling and the use of genetic information as a standard for access to healthcare clinics and jobs. The discussion of all these issues is essential to benefit public health with information obtained through population genomic analysis.
\end{abstract}

Key words Human Genome Project, Biotecnology, Ethics, Public health, Genetic counseling

\section{Resumo}

O presente artigo tem como objetivo contextualizar o campo da saúde pública diante dos grandes avanços da biotecnologia e genética aplicada, destacando elementos para a problematização do tema tais como benefícios $e$ questões éticas relacionados aos rastreamentos genéticos. O Projeto Genoma Humano gerou várias expectativas, dentre elas, a possibilidade de rastrear genes associados a doenças e comportamentos, e mais ainda, de intervir geneticamente no ser humano, levantando preocupações relativas ao renascimento da eugenia, ao aconselhamento genético, e ao uso da informação genética como critério de acesso aos planos de saúde e postos de trabalho. Uma discussão de todos esses tópicos é essencial para que a saúde pública seja beneficiada com as informações obtidas através da análise genômica das populações.

Palavras-chave Projeto Genoma Humano, Biotecnologia, Ética, Saúde pública, Aconselhamento genético 


\section{Introdução}

As experiências do monge Gregor Mendel com linhagens puras de ervilhas que se iniciaram em 1856 nos jardins do monastério em Brünn, e ignoradas até depois de sua morte, marcaram o início da genética moderna. A grande contribuição de Mendel foi demonstrar que as características hereditárias correspondem a unidades discretas, que são separadas e recombinadas de diversas maneiras em cada geração. Essas unidades discretas foram subseqüentemente chamadas de genes.1,2 Os estudos de Mendel formaram a base para o desenvolvimento da genética. Outra enorme contribuição para a medicina foi a descoberta da estrutura em dupla hélice do DNA por Watson e Crick em 1953.3 Em 2003, ano que se comemorou 50 anos dessa descoberta também foi alcançado um marco para a ciência: o seqüenciamento do genoma humano. O genoma é a totalidade do material genético de um indivíduo ou de uma espécie. O genoma pode ser comparado a um manual de instruções que guia as células desde o óvulo fecundado pelo espermatozóide durante o seu desenvolvimento até o final da vida de um organismo.

Khoury et al. 4 discutem qual seria a inserção dos conhecimentos sobre o genoma humano na saúde publica. Esses autores chamam a atenção para: a missão original da saúde pública que é assegurar os interesses da sociedade garantindo condições à manutenção da saúde; a integração das novas tecnologias genéticas e informações delas provenientes para aplicação em programas de saúde; e a integração entre genética e as demais sub-especialidades da medicina.

O presente artigo tem como objetivo contextualizar o campo da saúde pública diante dos grandes avanços da biotecnologia e genética aplicada, problematizando esse tema quanto aos benefícios e questões éticas relacionadas aos rastreamentos genéticos.

\section{Projeto Genoma Humano}

O Projeto Genoma Humano (PGH), um programa internacional previsto para durar 15 anos, teve início em 1990 com um custo estimado em três bilhões de dólares. Parte do seu financiamento anual (3 a 5\%), foi destinado ao estudo das implicações ética, legal e social relacionadas à informação genômica. 5 Tendo como objetivo mapear o genoma humano, o PGH produziu tecnologias automatizadas que a menores custos mapeiam, descrevem e identificam genes com rapidez e eficácia. A aplicação de tecnologias gené- ticas, além da capacidade de armazenamento, recuperação e distribuição de informações computadorizadas, tem acelerado a localização e identificação de genes envolvidos no desenvolvimento e expressão de um grande número de fenótipos e distúrbios genéticos. ${ }^{6}$ Muitas destas doenças de base hereditária manifestam-se nos primeiros anos de vida, tendo importância para a pediatria. Estima-se que um terço das admissões de crianças para internamento são devidas a causas de base genética. Portanto, os pediatras serão solicitados a assumirem papel de relevância na indicação de testes genéticos para seus pacientes e familiares. Além disso, deverão também comunicar o resultado destes testes levando em consideração todas as implicações éticas que envolvem esta situação. ${ }^{7}$

Algumas consequiências diretas do PGH devem ser mencionadas: a) a redução de custos dos exames inclusive para o consumidor, o que para a saúde publica é interessante; b) a concretização de possível base científica para o renascimento da "nova" eugenia, que no século XIX existia de maneira empírica; c) o estabelecimento de um modelo para a discussão de questões éticas levando em conta os preceitos da bioética, talvez ainda não de maneira satisfatória; d) todo conhecimento gerado e trazido para os consumidores também os faz demandar por mais assistência nos assuntos ligados à genética para que suas decisões sejam tomadas baseadas em explicações científicas e não apenas empíricas. De certa forma concede-se um certo poder decisório ao cidadão comum que passa agora a ter acesso a códigos genéticos, antes acessíveis apenas aos membros da equipe de saúde. Além disso, ele pode decidir sobre o destino de sua prole.

$\mathrm{O}$ PGH produziu expectativas com relação à identificação de genes específicos e suas relações com determinadas doenças.6,8 Por exemplo: as doenças poderiam ser conhecidas pelos seus genótipos e determinantes genéticos, e não apenas pelo fenótipo. Determinadas doenças poderiam ter evolução clínica diferente em pessoas com diferentes constituições genéticas; e haveria a possibilidade de redefinição de novos alvos terapêuticos baseados nos mecanismos das doenças e direcionados para subgrupos de pacientes com maior probabilidade de responder favoravelmente através de estudos de farmacocinética e farmacogenômica.

Obviamente, a possibilidade de identificar genes associados a doenças, susceptibilidades e comportamentos, e mais ainda, de intervir geneticamente no ser vivo principalmente humano, levanta questões éticas, legais e sociais. 6,8 Sobre esse tema, o recente artigo de Vieira ${ }^{9}$ contém informações de grande 
relevância no tocante às questões éticas que envolvem pesquisa com seres humanos. Revisa os principais estudos mundiais que suscitaram a necessidade de normatizar este tipo de abordagem científica, salientando a resolução 196/96 do Conselho Nacional de Saúde. Algumas das questões éticas relacionadas aos ras-treamentos genéticos serão discutidas adiante com mais detalhes.

\section{Rastreamento genético e eugenia}

Em geral, os princípios que justificam o rastreamento populacional baseiam-se na importância da doença para a saúde publica, na disponibilidade de um teste de rastreamento efetivo, na disponibilidade de medidas para prevenir a doença, e em considerações relativas a custos. O rastreamento genético de populações tem se concentrado: na identificação de pessoas com determinadas doenças hereditárias mendelianas, antes do aparecimento dos sintomas, visando prevenir a doença; no teste do estado de portador em populações selecionadas; e no uso de diagnóstico pré-natal para reduzir a freqüência da doença nas gerações subseqüentes. Contudo, a tendência atual é utilizar o rastreamento genético para detectar susceptibilidade individual a doenças comuns tais como, doenças cardíacas, diabetes e câncer.10,11 Esse tipo de rastreamento identificará grupos de risco permitindo que os esforços da prevenção sejam iniciados. Atualmente, mais de 900 testes genéticos estão disponíveis, 12 alguns deles apresentados na Tabela 1 . O rastreamento para diversas doenças genéticas tem como população alvo recém-nascidos ou crianças, ou mesmo mulheres grávidas. Para ilustrar, citemos a Doença de Huntington, cuja implicação clínica ou letalidade não é significativa em idade precoce. Esse exemplo ressalta a colocação de que, ao testar crianças para doenças que só se manifestarão em idade mais avançada, se eliminaria a autonomia dessas crianças sobre sua decisão a respeito desses testes. Com relação a esse tema, a Academia Americana de Pediatria bem como a American Society of Human Genetics recomendam que testes genéticos para identificação de portadores ou detecção de doença que só se manifestam em idade mais avançada, sejam postergados até a idade adulta ou até a adolescência. $8,13-16$

O desenvolvimento de tais testes pode estimular o renascimento da eugenia, movimento originalmente estabelecido por Francis Galton no século XIX. Galton era tido como entusiasta da seleção das espécies e de maneira empírica visava o aprimora-
Quadro 1

Principais patologias que dispõem de testes para rastreamento genético.

\begin{tabular}{|ll|}
\hline Deficiência de alfa 1 anti-tripsina & Distonia \\
Esclerose lateral amiotrófica & Anemia de Fanconi, grupo C \\
Doença de Alzheimer & Fator V deLeiden \\
Ataxia-telangiectasia & Síndrome do X frágil \\
Doença de Gaucher & Hemofilia A e B \\
Câncer de mama e ovário & Hemocromatose hereditária \\
Câncer de cólon & Doença de Huntington \\
Síndrome de Charcot-Marie-Tooth & Distrofia Miotônica \\
Hiperplasia adrenal congênita & Neurofibromatose tipo 1 \\
Fibrose cística & Fenilcetonúria \\
Distrofia muscular de Duchenne & Doença do rim policístico \\
Atrofia muscular espinhal & Síndromes Prader Willi/Angelman \\
Talassemias & Anemia falciforme \\
Doença Tay-Sachs & Ataxia espinocerebelar tipo 1 \\
\hline
\end{tabular}

Fonte: Adaptado: Gene testing. ${ }^{12}$

mento da raça humana. Naquela época vários programas foram estabelecidos enfatizando determinadas características desejáveis (eugenia positiva) e reprimindo as indesejáveis (eugenia negativa) de acordo com os problemas identificados como hereditários. A eugenia positiva se referia a programas educacionais e tinha como objetivo orientar o indivíduo a selecionar parceiros, premiar os bons reprodutores e a modificar convenções sociais sobre o casamento. A eugenia negativa incluía esterilização, institucionalização dos "débeis-mentais" ou "incapacitados", restrição a imigração (por considerar os imigrantes uma sub-raça) entre outras. 17 Sobre a eugenia Galtoniana pode-se dizer que ela era: não consentida, pois induzia uma esterilização forçada, sem direito a esclarecimento das causas; liderada por psicólogos, advogados, banqueiros, assim como por ativistas da classe média dos Estados Unidos e Reino Unido; criticada por sociólogos e reformistas que a encaravam como meritocracia biológica a qual substituiria o rígido sistema de classes sociais; e financiada pelo governo. O governo exercia então um papel primordial. Na Alemanha nazista a eugenia era um dos pilares da luta liderada por Hitler e todas as atrocidades realizadas naquela época foram resultantes da visão distorcida desta questão. ${ }^{6,18}$

No século XX e XXI surge a "nova" eugenia. Ao contrário da eugenia Galtoniana ("velha" eugenia), na "nova" eugenia a família, e não o indivíduo é o foco da questão. As mães principalmente passam a participar de forma voluntária na decisão de triagem genética para determinadas condições. De fato, a informação contida no DNA poderá transformar os 
pais em agentes eugênicos. Algumas decisões serão dificilmente adotadas, tomando como exemplo as questões a seguir: baseados em que critérios os pais decidirão a interrupção de uma gestação? Qual será o critério utilizado para se considerar um problema grave? Quando o teste sinalizar que o feto terá péchato? Miopia? Determinada cor de cabelo? Tais exemplos parecem caricaturas ou ficção, mas devem ser questionados. Nesses casos, a religião, questões filosóficas e a opinião da comunidade serão levadas em conta pelas famílias no processo decisório. 6 Também deve ser mencionado que haverá conflito de interesses entre geneticistas e laboratórios. Lucros e objetivos diversos estarão diretamente relacionados à mais ampla aplicação da tecnologia por eles desenvolvida.

A nova eugenia é liderada por geneticistas, médicos e conselheiros genéticos. Além disso, há uma grande conexão com a informática e informação genômica, permitindo poderosa influência no mercado capitalista uma vez que este serviço passa a ser oferecido como bem de consumo para o indivíduo e sua família.6,8 A palavra "nova" em contraposição a palavra "velha", precisa ser interpretada com cautela uma vez que traz a conotação otimista do novo que nem sempre é o melhor ou mais adequado.

\section{Outras questões éticas relacionadas aos rastreamentos genéticos}

A ética emite juízos de apreciação, estabelecendo as diretrizes e princípios para a orientação da conduta humana, de forma que esta seja compatível com o aperfeiçoamento pessoal e o bem comum da humanidade. Grande parte das bases conceituais que norteiam os rastreamentos genéticos são derivadas do principialismo. A teoria dos principialistas baseiase em quatro princípios: não-maleficência, beneficência, autonomia e equidade, 19 cuja hierarquização não é claramente definida porque depende da situação ou contexto do conflito. Particularmente, beneficência/não maleficência essencialmente ditam que o objetivo da medicina é fazer o bem e evitar o mal. A autonomia enfatiza a dignidade e respeito que devem ser mantidos em relação ao paciente, principalmente quanto à necessidade do mesmo autorizar e escolher o mais adequado tipo de tratamento para seu caso particular. Quanto à equidade e justiça, esses preceitos carregam em si a noção de equidade e imparcialidade de tratamento para todos os pacientes, além da igual distribuição de serviços médicos para a sociedade. 6 Mowat 20 chama atenção para a necessidade de acesso a bons serviços de genética que eduquem e capacitem os médicos a lidarem com os rastreamentos genéticos, principalmente a triagem familiar, testes preditivos e testes pré-natais ou pré-implantação. Contudo, o que torna o assunto complexo, é que existem outras correntes filosóficas que concordam em algumas situações e conflitam em outras, tais como o utilitarismo ${ }^{21}$ e filosofias Kantianas. ${ }^{22}$ No utilitarismo do ato, uma dada ação é julgada como certa ou errada na dependência exclusiva de suas consequiências. A base da premissa utilitarista é que tanto a ação individual como a política pública deve maximizar a "utilidade", que normalmente é definida em termos de felicidade ou satisfação, para o maior número de pessoas.21 Por sua vez, as filosofias Kantianas e Neo-Kantianas, apóiam a idéia de que a obrigação primária dos médicos é com seu paciente e não com as gerações futuras de pacientes. Kant se ocupava com a motivação da ação, argumentando que apenas o dever motivaria uma ação moralmente adequada. 22

Além das questões da eugenia, discutidas acima, existe uma preocupação que a informação genética possa interferir com a privacidade das pessoas, podendo eventualmente prejudicá-las. Wiesenthal e Wiener 11 ressaltam que as pessoas poderão não ser capazes de manter a privacidade de seus direitos face ao grande incentivo dado para o conhecimento do genoma individual. Neste sentido, existe grande preocupação com a possibilidade de discriminação com base no conhecimento do genótipo individual. Situações concretas seriam: o acesso aos planos de assistência privada de saúde, a seleção para postos de trabalho, seleção para ingresso em instituições de ensino, além da oportunidade na aquisição de empréstimos. 23

Existem várias questões abertas com relação a esses preceitos. Por exemplo, é razoável que seguradoras solicitem testes genéticos para determinar elegibilidade para cobertura de seus segurados? Assegurar saúde a todo custo pode requerer a proposta de um abortamento, caso esses testes indiquem que o embrião poderá ser acometido por alguma doença genética. Caso mantida a gestação, as seguradoras e promotores de saúde estão autorizados a recusar cobertura para este indivíduo?

Alguns questionam se o uso de recursos de impostos pagos por todos deva ser utilizado para pacientes portadores de deficiências que "poderiam ter sido evitadas". Wiesenthal e Wiener11 afirmam que recursos advindos de impostos pagos pela sociedade deveriam ser direcionados para programas de aconselhamento genético, desenvolvimento da nutrição infantil, financiamento de clínicas e hospi- 
tais, desenvolvimento de vacinas, etc. Os autores fazem uma pergunta que parece um tanto ou quanto árdua, mas pertinente: "É justo usar recursos dos impostos pagos pelos contribuintes para cobrir custos com uma criança com fibrose cística ou síndrome de Down?"6

Será que as pesquisas para tratamento e cura de desordens genéticas serão interrompidas uma vez que o rastreamento torne-se amplamente disponível? Ainda outra indagação pode ser feita. Estamos perto de ver testes genéticos realizados em casa como já existem para diabetes e gravidez? Estarão estes acessíveis a todos?

Ainda não há consenso sobre as ações que devem ser tomadas quando da detecção de genes de susceptibilidade. O câncer de mama é bastante prevalente entre as mulheres, sendo os genes BRCA 1 e BRCA 2 marcadores de susceptibilidade para essa patologia. Deveria a paciente em questão ter suas mamas removidas, mesmo que atualmente saudáveis? Esse procedimento cirúrgico seria ético? Deveria então, ser considerada a questão de custo/benefício entre cirurgia "profilática" X tratamento do câncer? Nos Estados Unidos a Myriad Genetics Inc. detém a patente para a identificação dos genes BRCA 1 e BRCA 2 para a triagem em massa. $\mathrm{O}$ teste para detectar tais genes custa cerca de 3.000 dólares. Nestes casos mais uma consideração deverá ser feita no tocante a relação clientes com convênios de saúde. Alguns convênios não pagam esses testes e se pagam, há o risco da perda de confidencialidade do paciente. Além disso, nem todas as mulheres terão acesso a esses exames.

Outro exemplo a citar é de um rastreamento genético realizado em judeus de Nova York na década de 90 visando identificar os genes da doença de Tay-Sachs, fibrose cística e doença de Gaucher, uma vez que aquele povo tem o hábito do casamento entre pessoas do mesmo grupo. Após serem avisados do risco genético como resultado do teste de triagem, muitos casais desfizeram o casamento. Que solução poderia ser sugerida para evitar tais casos?

Por outro lado, Beckman 24 contrapõe que a autonomia individual não é reduzida ou aniquilada pelas informações genéticas, mas pelas interpretações errôneas e mal entendidos oriundos dos resultados destes testes. Para evitar isso políticas de mercado quanto ao uso e utilidade dos mesmos devem ser rigorosamente estudadas.

Wiesenthal e Wiener11 alertam ainda para o problema da "biologização" dos problemas sociais (crime, violência, desordem) como uma maneira de desviar a atenção de questões ambientais e sociais, já que existem correntes científicas que imputam aos genes, determinadas características comportamentais. Esses autores também ressaltam que usando o prestígio do $\mathrm{PGH}$, indivíduos podem não ser vistos como responsáveis pelos seus atos, desde que o crime possa então ser caracterizado como oriundo do conjunto de genes defeituosos. Seria a valorização da alteração genética como causa dos defeitos "sociais".

\section{Comentários finais}

O rastreamento genético por si só não tem sentido a menos que seja seguido de aconselhamento genético. Este só é eticamente defensável se: as propostas e objetivos são claramente definidos; estudos piloto são realizados para avaliação de custo-benefício; é fornecida educação a população alvo; e é respeitado o sigilo das informações estigmatizantes. 25 Além disso, questões sociais, culturais, religiosas entre outras também deverão ser consideradas quando da implantação de programas de rastreamento genético.

Diante desta nova realidade e frente à avalanche de trabalhos publicados sobre o genoma humano e rastreamentos genéticos, o Center for Disease Control and Prevention (CDC) e o National Institute of Health (NIH) promoveram em 2001, uma reunião envolvendo médicos, geneticistas, epidemiologistas, estatísticos, biólogos, biomédicos e sociólogos para avaliar os dados de estudos epidemiológicos do PGH. Nessa reunião foram discutidos exemplos extraídos do estudo do câncer, das doenças cardiovasculares, da infecção pelo Human Immunodeficiency Vírus (HIV) e de outras áreas. As questões abordadas pelos participantes levaram em consideração não só as variações genéticas, mas também as interações de genes com o meio ambiente e a necessidade de melhores métodos de avaliação para os testes genéticos disponíveis. 4

A preocupação com a prevenção de agravos e promoção da saúde continua sendo fortemente defendida, no século XXI, para a prática médica e para a saúde pública como demonstrado em vários programas de triagem genética. 26,27 Finalmente, a questão maior é se, de fato, a saúde publica será melhorada ou beneficiada com as informações obtidas através da análise genômica das populações. Três pontos encontram-se vinculados a essa questão: acesso ao teste; disponibilidade de intervenção e motivação das pessoas em modificarem os seus hábitos em função dos resultados dos testes. 24

O Projeto Genoma Humano gerou várias expectativas, dentre elas, a possibilidade de rastrear genes associados a doenças e comportamentos, e mais 
ainda, de intervir geneticamente no ser humano, trazendo benefícios sociais. Contudo, haja vista a novidade, complexidade e amplitude do assunto é natural que existam opiniões discordantes e questões ainda abertas, com relação a como isto deve ocorrer. Portanto, por um lado deve-se evitar o radicalismo intransigente, mas, por outro lado, também são inaceitáveis as flexibilizações motivadas por interesses pessoais ou grupais. Está claro para nós, que para que possa haver uma integração das novas tecnologias de rastreamentos genéticos para bene-

\section{Referências}

1. Curtis H. Biologia. 2. ed. Rio de Janeiro: Guanabara Koogan; 1977. Cap. 11. p. 115-78.

2. Griffths AF, Gelbart WM, Miller JH, Lewotin RC. Genética moderna. Rio de Janeiro: Guabara Koogan; 2001.

3. Watson J, Crick F. Molecular structure of nucleic acids. A structure for deoxyribose nucleic acid 1953. Rev Invest Clin 2003; 55: 108-9.

4. Khoury MJ. Commentary: epidemiology and the continuum from genetic research to genetic testing. Am J Epidemiol 2002; 156: 297-9.

5. Lapham EV, Kozma C, Weiss JO. Genetic discrimination: perspectives of consumers. Science 1996; 274: 621-4.

6. Wiesenthal DL, Wiener NI. Ethical questions in the age of the new eugenics. Sci Eng Ethics 1999; 5: 383-94.

7. Rosen A, Wallenstein S, McGovern. Attitudes of pediatrics residents toward ethical issues associated with genetic testing in children. Pediatrics 2002; 110: 360-3.

8. Cardoso MHCA, Castiel LD. Saúde coletiva, nova genética e a eugenia de mercado. Cad Saúde Pública 2003; 19: 65362.

9. Vieira S. Ética e metodologia na pesquisa médica. Rev Bras Saúde Materno Infantil 2005; 5: 241-5.

10. Hopper JL. Application of genetic to the prevention of colorectal cancer. Recent Resuts Cancer Res 2005; 166: 17-33.

11. Wiesenthal DL, Wiener NI. Privacy and the human genome project. Ethics Behav 1997; 6: 189-201.

12.Gene testing. Disponível em URL: http://www.ornl.gov/ TechResources/Human_Genome/medicine/genetest.html\# whatis (2005 Mar 7).

13. ASHG (American Society of Human Genetics) Board of Directors, ACMG (American College of Medical Genetics), Board of Directors. Points to consider: ethical, legal, and psychological implications of genetic testing in children and adolescents. Am J Hum Genet 1995; 57: 1233-1241.

14. American Academy of Pediatrics. Committee on Bioethics. Ethical issues with genetic testing in pediatrics. Pediatrics 2001; 107: 1451-5. fício da saúde pública, o conhecimento de várias disciplinas é indispensável. Além disto, estas ações devem ser coordenadas dentro de padrões éticos. Finalmente, em vista da enorme importância e potenciais consequiências para a sociedade do tema aqui brevemente discutido, é necessário que o assunto seja posto em discussão não apenas nos centros de pesquisa e universidades, mas também nos espaços sociais que permitam um debate público mais abrangente.

15. American Academy of Pediatrics, Committee on Genetics. Molecular genetic testing in pediatric pratice: a subject review. Pediatrics 2000; 106: 1494-7.

16. Cunniff $C$. Prenatal screening and diagnosis for pediatricians. Pediatrics 2004; 114: 889-94.

17. Kelves D. In the name of eugenics: genetics and the uses of human heredity. Berkeley: University of California Press; 1986.

18. Burnham T, Phelan J. A culpa é da genética. Rio de Janeiro; Sextante; 2002.

19. Beauchamp TL, Chidress J. Principles of biomedical ethics. New York: Oxford University Press; 1994.

20. Mowat D. Ehical legal and social issues surrounding the human genome project. Intern Med J 2002; 32: 89-90.

21. Unger P. Living high and letting dye: our illusion of innocence. New York: Oxford University Press; 1996

22. Bunnin N, Tsui-James EP, editors. Compêndio de filosofia. São Paulo: Edições Loyola; 2002.

23. Clayton EW. Ethical, legal and social implications of genomic medicine. N Eng J Med 2003; 349: 562-9.

24. Beckman L. Are genetic self-tests dangerous? Assessing the commercialization of genetic testing in terms of personal autonomy. Theor Med Bioeth 2004; 25: 387-98.

25. Fost N. Ethical issues in genetics. Peditr Clin North Am 1992; 39: 79-89.

26. Basset K, Lee PM, Green CJ, Michel L, Kazanjian A. Improving population health or the population it self? Health technology assessement and our genetic future. Intern J Assessement Health Care 2004; 20: 106-14.

27. Njajou OT, Alizadeh BZ, van Dujin CM. Is genetic screen for hemochromatoses worthwhile? Eur J Epidemiol 2004;19: 101-8. 